\title{
New aspects of Opial-type integral inequalities
}

\author{
Yasemin BaşCl ${ }^{1 *}$ and Dumitru Baleanu ${ }^{2,3}$
}

\author{
"Correspondence: \\ basci_y@ibu.edu.tr \\ 1 Department of Mathematics, \\ Faculty of Arts and Sciences, Bolu \\ Abant Izzet Baysal University, Bolu, \\ Turkey \\ Full list of author information is \\ available at the end of the article
}

\begin{abstract}
In this manuscript, we prove new aspects for several Opial-type integral inequalities for the left and right Caputo-Fabrizio operators with nonsingular kernel. For this purpose we use the inequalities obtained by Andrić et al. (Integral Transforms Spec. Funct. 25(4):324-335, 2014), which is the generalization of an inequality of Agarwal and Pang (Opial Inequalities with Applications in Differential and Difference Equations, 1995). Besides, examples are presented to validate the reported results.
\end{abstract}

MSC: 26D10; 26D15; 26A33; 26A40; 26A42; 26A51

Keywords: Opial-type inequality; The left operator; The right operator; The left integral; The right integral; Caputo-Fabrizio fractional derivative

\section{Introduction and preliminaries}

Since the discovery of Opial's inequality, it has found interesting applications. Really, Opial's inequality and its generalizations, extensions, and discretizations have been playing an important role in the study of the existence and uniqueness of initial and boundary value problems for ordinary and partial differential equations besides difference equations $[3,4,21,39,42]$.

In 1960, Opial [43] obtained the following integral inequality:

Theorem 1.1 Let $x(t) \in C^{1}[0, h]$ be such that $x(0)=x(h)=0$ and $x(t)>0$ in $(0, h)$. Then the following integral inequality holds:

$$
\int_{0}^{h}\left|x(t) x^{\prime}(t)\right| d t \leq \frac{h}{4} \int_{0}^{h}(x(t))^{2} d t
$$

Here $\frac{h}{4}$ is a constant best possibility.

From that time, Opial's inequality [43] has been studied extensively by many mathematicians. This inequality has been extended, generalized in different ways, see $[2,5,6$, $22,24-28,39,40,44-47,54]$. Also, various mathematicians studied Opial-type integral inequalities for different types of fractional derivative and integral operators involving Caputo, Canavati, Riemann-Liouville, and so on, see $[9,14,16-19,29-31]$ and the references therein.

(c) The Author(s) 2018. This article is distributed under the terms of the Creative Commons Attribution 4.0 International License (http://creativecommons.org/licenses/by/4.0/), which permits unrestricted use, distribution, and reproduction in any medium, provided you give appropriate credit to the original author(s) and the source, provide a link to the Creative Commons license, and indicate if changes were made. 
In 2000, Anastassiou [7] obtained Opial-type inequalities involving functions and their ordinary and fractional derivatives. In 2002, Anastassiou and Goldstein [12] presented the Opial-type inequalities involving fractional derivatives of different orders. The same year, Anastassiou et al. [13] studied a class of $L_{p}$-type Opial inequalities for generalized fractional derivatives for integrable functions based on the results obtained earlier by the first author in 1998. In 2004, Anastassiou [8] established the Opial-type inequalities including fractional derivatives of two functions in different order and power. In 2008, he presented Opial-type inequalities involving Riemann-Liouville fractional derivatives of two functions with applications, see [9]. Also, in 2009, he presented fractional Opial-type inequalities subject to high order boundary conditions in $L_{p}$ for $p>1$, and in 2012, he extended Opial's integral inequality using the right and left Caputo as well as Riemann-Liouville fractional derivatives, respectively, see $[10,11]$.

In 2013, Andrić et al. [17] obtained several Opial-type inequalities including Caputo, Canavati, and Riemann-Liouville fractional derivatives. The same year, they presented developments of composition identities for the Caputo fractional derivatives. They gave applications to Opial-type inequalities in [18]. Also, the same year, they studied some Opial-type inequalities for Riemann-Liouville fractional derivatives obtained by Fink in [34] and Pang and Agarwal in [48], see [19].

In 2014, Andrić et al. [15] gave expansions of the Opial-type integral inequalities. Also, they presented a generalization of an inequality obtained by Agarwal and Pang [4].

In 2015, Farid et al. [32] studied the Opial-type inequalities by using generalized fractional integral operator including the Mittag-Leffler function in the kernel. One year later, they presented Opial-type integral inequalities for Hilfer differential and fractional integral operators involving a generalized Mittag-Leffler function in the kernel, see [33].

In 2017, Tomovski et al. [53] gave the generalization of weighted Opial-type inequalities for fractional integral and differential operators involving generalized Mittag-Leffler functions by using Hölder's integral inequality motivated by the work of Koliha and Pečarić [38].

In 2017, Sarkaya and Budak [50] obtained new inequalities of Opial-type for conformable integrals.

Recently, researchers have proposed different fractional-time operators from the wellknown Riemann-Liouville operator, see [20,35-37, 52]. They are defined by nonsingular memory kernels. Also, they used these new operators to generalize the usual diffusion equation. In fact, these new operators can describe better the evolution of some dynamics of complex systems which cannot be done within the standard fractional calculus operators (for more details, see Refs. [35-37] and the references therein).

The purpose of this paper is to establish some Opial-type integral inequalities for the left and right operators with nonsingular kernel. The organization of this paper is given below. The introduction is given in Sect. 1. In Sect. 2, basic definitions and theorems are introduced. Motivated by [4] and [15], we establish several Opial-type inequalities in Sect. 3. Several examples are given for our results in Sect. 4.

\section{Basic definitions and theorems}

In this section, we present the following theorems, corollaries, and definitions which are useful in the proofs of our results. 
Let $U_{1}\left(u, K_{1}\right)$ denote the class of functions $v:\left[a_{1}, b_{1}\right] \rightarrow \mathbb{R}$ with the representation

$$
v(t)=\int_{a_{1}}^{t} K_{1}(t, s) u(s) d s .
$$

Here, the function $u$ is continuous and $K_{1}$ is an arbitrary nonnegative kernel function such that $u(t)>0$ implies $v(t)>0$ for all $t \in\left[a_{1}, b_{1}\right]$. Similarly, let $U_{2}\left(u, K_{1}\right)$ denote the class of functions $v:\left[a_{1}, b_{1}\right] \rightarrow \mathbb{R}$ with the representation

$$
v(t)=\int_{t}^{b_{1}} K_{1}(t, s) u(s) d s
$$

We suppose that all integrals exist. Also, they are finite.

Theorem 2.1 ([15]) Let $\psi:[0, \infty) \rightarrow \mathbb{R}$ be a differentiable function such that, for $q_{1}>1, \psi\left(t^{1 / q_{1}}\right)$ is a convex function and $\psi(0)=0$. Also, let $v \in U_{1}\left(u, K_{1}\right)$ such that $\left(\int_{a_{1}}^{t}\left(K_{1}(t, s)\right)^{p_{1}} d s\right)^{1 / p_{1}} \leq C$ and $\frac{1}{p_{1}}+\frac{1}{q_{1}}=1$. Then

$$
\begin{aligned}
& \int_{a_{1}}^{b_{1}}|v(t)|^{1-q_{1}} \psi^{\prime}(|v(t)|)|u(t)|^{q_{1}} d t \\
& \quad \leq \frac{q_{1}}{C^{q_{1}}} \psi\left(C\left(\int_{a_{1}}^{b_{1}}|u(t)|^{q_{1}} d t\right)^{1 / q_{1}}\right) \\
& \quad \leq \frac{q_{1}}{C^{q_{1}}\left(b_{1}-a_{1}\right)} \int_{a_{1}}^{b_{1}} \psi\left(\left(b_{1}-a_{1}\right)^{1 / q_{1}} C|u(t)|\right) d t .
\end{aligned}
$$

If $\psi\left(t^{1 / q_{1}}\right)$ is a concave function, then reverse inequalities are valid.

When $\psi(x)=t^{p_{1}+q_{1}}$, the following corollary is obtained.

Corollary $2.1([15])$ Let $v \in U_{1}\left(u, K_{1}\right)$ where $\left(\int_{a_{1}}^{t}\left(K_{1}(t, s)\right)^{p_{1}} d s\right)^{1 / p_{1}} \leq C$ and $\frac{1}{p_{1}}+\frac{1}{q_{1}}=1$. Then

$$
\begin{aligned}
\int_{a_{1}}^{b_{1}}|v(t)|^{p_{1}}|u(t)|^{q_{1}} d t & \leq \frac{q_{1} C^{p_{1}}}{p_{1}+q_{1}}\left(\int_{a_{1}}^{b_{1}}|u(t)|^{q_{1}} d t\right)^{\left(p_{1}+q_{1}\right) / q_{1}} \\
& \leq \frac{q_{1} C^{p_{1}}\left(b_{1}-a_{1}\right)^{p_{1} / q_{1}}}{p_{1}+q_{1}} \int_{a_{1}}^{b_{1}}|u(t)|^{p_{1}+q_{1}} d t .
\end{aligned}
$$

Theorem 2.2 ([15]) Let the function $\psi:[0, \infty) \rightarrow \mathbb{R}$ be differentiable such that, for $q_{1}>1, \psi\left(t^{1 / q_{1}}\right)$ is a convex function and $\psi(0)=0$. Let $v \in U_{2}\left(u, K_{1}\right)$ such that $\left(\int_{t}^{b_{1}}\left(K_{1}(t\right.\right.$, $\left.s))^{p_{1}} d s\right)^{1 / p_{1}} \leq C$ and $\frac{1}{p_{1}}+\frac{1}{q_{1}}=1$. Then

$$
\begin{aligned}
& \int_{a_{1}}^{b_{1}}|v(t)|^{1-q_{1}} \psi^{\prime}(|v(t)|)|u(t)|^{q_{1}} d t \\
& \quad \leq \frac{q_{1}}{C^{q_{1}}} \psi\left(C\left(\int_{a_{1}}^{b_{1}}|u(t)|^{q_{1}} d t\right)^{1 / q_{1}}\right) \\
& \quad \leq \frac{q_{1}}{C^{q_{1}}\left(b_{1}-a_{1}\right)} \int_{a_{1}}^{b_{1}} \psi\left(\left(b_{1}-a_{1}\right)^{1 / q_{1}} C|u(t)|\right) d t .
\end{aligned}
$$

If $\psi\left(t^{1 / q_{1}}\right)$ is a concave function, then reverse inequalities are valid. 
When $\psi(x)=t^{p_{1}+q_{1}}$, the following corollary is obtained.

Corollary 2.2 ([15]) Let $v \in U_{2}\left(u, K_{1}\right)$ where $\left(\int_{t}^{b_{1}}\left(K_{1}(t, s)\right)^{p_{1}} d s\right)^{1 / p_{1}} \leq C$ and $\frac{1}{p_{1}}+\frac{1}{q_{1}}=1$. Then

$$
\begin{aligned}
\int_{a_{1}}^{b_{1}}|v(t)|^{p_{1}}|u(t)|^{q_{1}} d t & \leq \frac{q_{1} C^{p_{1}}}{p_{1}+q_{1}}\left(\int_{a_{1}}^{b_{1}}|u(t)|^{q_{1}} d t\right)^{\left(p_{1}+q_{1}\right) / q_{1}} \\
& \leq \frac{q_{1} C^{p_{1}}\left(b_{1}-a_{1}\right)^{p_{1} / q_{1}}}{p_{1}+q_{1}} \int_{a_{1}}^{b_{1}}|u(t)|^{p_{1}+q_{1}} d t .
\end{aligned}
$$

Below, we show the definitions of the left and right operators with nonsingular kernel introduced in [23]. According to [1,23], if $g \in H^{1}\left(a_{1}, b_{1}\right), 0<a_{1}<b_{1} \leq \infty, \alpha \in(0,1)$, the left operator ${ }_{a_{1}}^{C F R} D^{\alpha}$ is defined by

$$
\left({ }_{a_{1}}^{C F R} D^{\alpha} g\right)(t)=\frac{M(\alpha)}{1-\alpha} \frac{d}{d t} \int_{a_{1}}^{t} g(s) \exp (\lambda(t-s)) d s
$$

and the right operator ${ }^{C F R} D_{b_{1}}^{\alpha}$ is defined by

$$
\left({ }^{C F R} D_{b_{1}}^{\alpha} g\right)(t)=-\frac{M(\alpha)}{1-\alpha} \frac{d}{d t} \int_{t}^{b_{1}} g(s) \exp (\lambda(s-t)) d s,
$$

with $\lambda=-\frac{\alpha}{1-\alpha}$ and $t \geq a_{1}$. Here $M(\alpha)$ is a normalization function depending on $\alpha$. Also, the left integral operator is defined as

$$
\left({ }_{a_{1}}^{C F} I^{\alpha} g\right)(t)=\frac{1-\alpha}{B(\alpha)} g(t)+\frac{\alpha}{B(\alpha)} \int_{a_{1}}^{t} g(s) d s
$$

and the right integral operator is defined as

$$
\left({ }^{C F} I_{b_{1}}^{\alpha} g\right)(t)=\frac{1-\alpha}{B(\alpha)} g(t)+\frac{\alpha}{B(\alpha)} \int_{t}^{b_{1}} g(s) d s
$$

Definition 2.1 ([49]) Let $f$ and $g$ be two functions that are piecewise continuous on every finite closed interval $0 \leq t \leq b$ and of exponential order. The function denoted by $f * g$ and defined by

$$
f(t) * g(t)=\int_{0}^{t} f(s) g(t-s) d s
$$

is called the convolution of the functions $f$ and $g$.

Definition 2.2 ([51]) Let $f(x)$ and $g(x)$ be positive and be in $L^{1}$. Moreover, they are differentiable and their derivative is integrable. Then the derivative of a convolution is

$$
(f * g)^{\prime}=f^{\prime} * g=f * g^{\prime} .
$$




\section{Main results}

In this section, we give the Opial-type integral inequalities for the left and right of the operator using the inequalities obtained by Andrić et al. [15], which is the generalization of an inequality of Agarwal and Pang [4].

The following result is obtained by using Theorem 2.1 and the left operator.

Theorem 3.1 Let $\psi:[0, \infty) \rightarrow \mathbb{R}$ be a differentiable function such that, for $q_{1}>1, \psi\left(t^{1 / q_{1}}\right)$ is a convex function and $\psi(0)=0$. Also, let $0<\alpha<1, g \in H^{1}\left(a_{1}, b_{1}\right)$, and let ${ }_{a_{1}}^{C F R} D^{\alpha}$ be defined by (2.6). If $\frac{1}{p_{1}}+\frac{1}{q_{1}}=1$, then the following inequalities hold:

$$
\begin{aligned}
& \int_{a_{1}}^{b_{1}}\left|\left({ }_{a_{1}}^{C F R} D^{\alpha} g\right)(t)\right|^{1-q_{1}} \psi^{\prime}\left(\left|\left({ }_{a_{1}}^{C F R} D^{\alpha} g\right)(t)\right|\right)\left|g^{\prime}(t)\right|^{q_{1}} d t \\
& \quad \leq \frac{q_{1}}{C^{q_{1}}} \psi\left(C\left(\int_{a_{1}}^{b_{1}}\left|g^{\prime}(t)\right|^{q_{1}} d t\right)^{1 / q_{1}}\right) \\
& \quad \leq \frac{q_{1}}{C^{q_{1}}\left(b_{1}-a_{1}\right)} \int_{a_{1}}^{b_{1}} \psi\left(\left(b_{1}-a_{1}\right)^{1 / q_{1}} C\left|g^{\prime}(t)\right|\right) d t,
\end{aligned}
$$

where

$$
C=\frac{M(\alpha)}{1-\alpha}\left(\frac{1-\exp \left(p_{1} \lambda\left(b_{1}-a_{1}\right)\right)}{-p_{1} \lambda}\right)^{1 / p_{1}} .
$$

If $\psi\left(t^{1 / q_{1}}\right)$ is a concave function, then reverse inequalities hold.

Proof For $t \in\left[a_{1}, b_{1}\right]$, let

$$
\begin{aligned}
& v(t)=\left({ }_{a_{1}}^{C F R} D^{\alpha} g\right)(t)=\frac{M(\alpha)}{1-\alpha} \frac{d}{d t} \int_{a_{1}}^{t} g(s) \exp (\lambda(t-s)) d s \\
& =\frac{M(\alpha)}{1-\alpha} \frac{d}{d t}(g(t) * \exp (\lambda t)) \\
& =\frac{M(\alpha)}{1-\alpha}\left(\frac{d g}{d t}(t) * \exp (\lambda t)\right) \\
& =\frac{M(\alpha)}{1-\alpha} \int_{a_{1}}^{t} g^{\prime}(s) \exp (\lambda(t-s)) d s, \\
& K_{1}(t, s)= \begin{cases}\frac{M(\alpha)}{1-\alpha} \exp (\lambda(t-s)), & a_{1} \leq s \leq t \\
0, & t \leq s \leq b_{1}\end{cases}
\end{aligned}
$$

and

$$
\phi(t)=\left(\int_{a_{1}}^{t}\left(K_{1}(t, s)\right)^{p_{1}} d s\right)^{1 / p_{1}}=\frac{M(\alpha)}{1-\alpha}\left(\frac{1-\exp \left(p_{1} \lambda\left(t-a_{1}\right)\right)}{-p_{1} \lambda}\right)^{1 / p_{1}} .
$$

From $\lambda<0$, the function $\phi$ is increasing on $\left[a_{1}, b_{1}\right]$. Thus, we can write

$$
\max _{t \in\left[a_{1}, b_{1}\right]} \phi(t)=\frac{M(\alpha)}{1-\alpha}\left(\frac{1-\exp \left(p_{1} \lambda\left(b_{1}-a_{1}\right)\right)}{-p_{1} \lambda}\right)^{1 / p_{1}}=C .
$$


Then $\left(\int_{a_{1}}^{t}\left(K_{1}(t, s)\right)^{p_{1}} d s\right)^{1 / p_{1}} \leq C$. Also, if it is taken as $u=g^{\prime}$ and $v$ as in (3.3), then from Theorem 2.1 it gives us (3.1) in Theorem 3.1. This completes the proof.

When $\psi(t)=t^{p_{1}+q_{1}}$ in Theorem 3.1, the following corollary is obtained.

Corollary 3.1 Let $0<\alpha<1, g \in H^{1}\left(a_{1}, b_{1}\right)$, and let ${ }_{a_{1}}^{C F R} D^{\alpha}$ be defined by (2.6). Also let $\frac{1}{p_{1}}+$ $\frac{1}{q_{1}}=1$. Then the following inequalities hold:

$$
\begin{aligned}
\int_{a_{1}}^{b_{1}}\left|\left({ }_{a_{1}}^{C F R} D^{\alpha} g\right)(t)\right|^{p_{1}}\left|g^{\prime}(t)\right|^{q_{1}} d t & \leq \frac{q_{1} C^{p_{1}}}{p_{1}+q_{1}}\left(\int_{a_{1}}^{b_{1}}\left|g^{\prime}(t)\right|^{q_{1}} d t\right)^{\left(p_{1}+q_{1}\right) / q_{1}} \\
& \leq \frac{q_{1} C^{p_{1}}\left(b_{1}-a_{1}\right)^{p_{1} / q_{1}}}{p_{1}+q_{1}} \int_{a_{1}}^{b_{1}}\left|g^{\prime}(t)\right|^{p_{1}+q_{1}} d t
\end{aligned}
$$

where $C$ is defined as in (3.2).

Theorem 3.2 Let the function $\psi:[0, \infty) \rightarrow \mathbb{R}$ be differentiable such that, for $q_{1}>1$, $\psi\left(t^{1 / q_{1}}\right)$ is a convex function and $\psi(0)=0$. Also, let $0<\alpha<1, g \in H^{1}\left(a_{1}, b_{1}\right)$, and let ${ }^{C F R} D_{b_{1}}^{\alpha}$ be defined by (2.7). If $\frac{1}{p_{1}}+\frac{1}{q_{1}}=1$, then the following inequalities hold:

$$
\begin{aligned}
& \int_{a_{1}}^{b_{1}}\left|\left({ }^{C F R} D_{b_{1}}^{\alpha} g\right)(t)\right|^{1-q_{1}} \psi^{\prime}\left(\left|\left({ }^{C F R} D_{b_{1}}^{\alpha} g\right)(t)\right|\right)\left|g^{\prime}(t)\right|^{q_{1}} d t \\
& \quad \leq \frac{q_{1}}{C^{q_{1}}} \psi\left(C\left(\int_{a_{1}}^{b_{1}}\left|g^{\prime}(t)\right|^{q_{1}} d t\right)^{1 / q_{1}}\right) \\
& \quad \leq \frac{q_{1}}{C^{q_{1}}\left(b_{1}-a_{1}\right)} \int_{a_{1}}^{b_{1}} \psi\left(\left(b_{1}-a_{1}\right)^{1 / q_{1}} C\left|g^{\prime}(t)\right|\right) d t,
\end{aligned}
$$

where $C$ is defined as in (3.2). If $\psi\left(t^{1 / q_{1}}\right)$ is a concave function, then reverse inequalities hold.

Proof Using the same method as the proof of Theorem 3.1, inequalities follow from Theorem 2.2.

When $\psi(t)=t^{p_{1}+q_{1}}$ in Theorem 3.2, the following corollary is obtained.

Corollary 3.2 Let $0<\alpha<1, g \in H^{1}\left(a_{1}, b_{1}\right)$, and let ${ }^{C F R} D_{b_{1}}^{\alpha}$ be defined by (2.7). Also let $\frac{1}{p_{1}}+\frac{1}{q_{1}}=1$. Then the following inequalities hold:

$$
\begin{aligned}
\int_{a_{1}}^{b_{1}}\left|\left({ }^{C F R} D_{b_{1}}^{\alpha} g\right)(t)\right|^{p_{1}}\left|g^{\prime}(t)\right|^{q_{1}} d t & \leq \frac{q_{1} C^{p_{1}}}{p_{1}+q_{1}}\left(\int_{a_{1}}^{b_{1}}\left|g^{\prime}(t)\right|^{q_{1}} d t\right)^{\left(p_{1}+q_{1}\right) / q_{1}} \\
& \leq \frac{q_{1} C^{p_{1}}\left(b_{1}-a_{1}\right)^{p_{1} / q_{1}}}{p_{1}+q_{1}} \int_{a_{1}}^{b_{1}}\left|g^{\prime}(t)\right|^{p_{1}+q_{1}} d t
\end{aligned}
$$

where $C$ is defined as in (3.2).

The next result is obtained by using Theorem 2.1 and the left integral operator, see for more details [41]. 
Theorem 3.3 Let the function $\psi:[0, \infty) \rightarrow \mathbb{R}$ be differentiable such that, for $q_{1}>1$, $\psi\left(t^{1 / q_{1}}\right)$ is a convex function and $\psi(0)=0$. Also, let $0<\alpha<1, g \in H^{1}\left(a_{1}, b_{1}\right)$, and let ${ }_{a_{1}}^{C F} I^{\alpha}$ be defined by (2.8). If $\frac{1}{p_{1}}+\frac{1}{q_{1}}=1$, then the following inequalities hold:

$$
\begin{aligned}
& \int_{a_{1}}^{b_{1}}\left|\left({ }_{a_{1}}^{C F} I^{\alpha} g\right)(t)-\frac{1-\alpha}{B(\alpha)} g(t)\right|^{1-q_{1}} \psi^{\prime}\left(\left|\left(\begin{array}{c}
C F \\
a_{1}
\end{array} I^{\alpha} g\right)(t)-\frac{1-\alpha}{B(\alpha)} g(t)\right|\right)|g(t)|^{q_{1}} d t \\
& \quad \leq \frac{q_{1}}{C_{1}^{q_{1}}} \psi\left(C_{1}\left(\int_{a_{1}}^{b_{1}}|g(t)|^{q_{1}} d t\right)^{1 / q_{1}}\right) \\
& \quad \leq \frac{q_{1}}{C_{1}^{q_{1}}\left(b_{1}-a_{1}\right)} \int_{a_{1}}^{b_{1}} \psi\left(\left(b_{1}-a_{1}\right)^{1 / q_{1}} C_{1}|g(t)|\right) d t,
\end{aligned}
$$

where

$$
C_{1}=\frac{\alpha}{B(\alpha)}\left(b_{1}-a_{1}\right)^{1 / p_{1}}
$$

If $\psi\left(t^{1 / q_{1}}\right)$ is a concave function, then reverse inequalities hold.

Proof For $t \in\left[a_{1}, b_{1}\right]$, let

$$
\begin{aligned}
& v(t)=\left({ }_{a_{1}}^{C F} I^{\alpha} g\right)(t)-\frac{1-\alpha}{B(\alpha)} g(t), \\
& K_{1}(t, s)= \begin{cases}\frac{\alpha}{B(\alpha)}, & a_{1} \leq s \leq t ; \\
0, & t \leq s \leq b_{1},\end{cases}
\end{aligned}
$$

and

$$
\phi(t)=\left(\int_{a_{1}}^{t}\left(K_{1}(t, s)\right)^{p_{1}} d s\right)^{1 / p_{1}}=\frac{\alpha}{B(\alpha)}\left(t-a_{1}\right)^{1 / p_{1}} .
$$

From $\lambda<0$, the function $\phi$ is increasing on $\left[a_{1}, b_{1}\right]$. Thus, we can write

$$
\max _{t \in\left[a_{1}, b_{1}\right]} \phi(t)=\frac{\alpha}{B(\alpha)}\left(b_{1}-a_{1}\right)^{1 / p_{1}}=C_{1} .
$$

Then $\left(\int_{a_{1}}^{t}\left(K_{1}(t, s)\right)^{p_{1}} d s\right)^{1 / p_{1}} \leq C_{1}$. Also, if it is taken as $u=g$ and $v$ as in (3.9), then from Theorem 2.1 it gives us (3.7) in Theorem 3.3. This completes the proof.

When $\psi(t)=t^{p_{1}+q_{1}}$ in Theorem 3.3, we obtain the following corollary.

Corollary 3.3 Let $0<\alpha<1, g \in H^{1}\left(a_{1}, b_{1}\right)$, and let ${ }_{a_{1}}^{C F} I^{\alpha}$ be defined by (2.8). Also let $\frac{1}{p_{1}}+$ $\frac{1}{q_{1}}=1$. Then the following inequalities hold:

$$
\begin{gathered}
\int_{a_{1}}^{b_{1}}\left|\left({ }_{a_{1}}^{C F} I^{\alpha} g\right)(t)-\frac{1-\alpha}{B(\alpha)} g(t)\right|^{p_{1}}|g(t)|^{q_{1}} d t \\
\leq \frac{q_{1} C_{1}^{p_{1}}}{p_{1}+q_{1}}\left(\int_{a_{1}}^{b_{1}}|g(t)|^{q_{1}} d t\right)^{\left(p_{1}+q_{1}\right) / q_{1}}
\end{gathered}
$$




$$
\leq \frac{q_{1} C_{1}^{p_{1}}\left(b_{1}-a_{1}\right)^{p_{1} / q_{1}}}{p_{1}+q_{1}} \int_{a_{1}}^{b_{1}}|g(t)|^{p_{1}+q_{1}} d t
$$

where $C_{1}$ is defined as in (3.8).

Theorem 3.4 Let the function $\psi:[0, \infty) \rightarrow \mathbb{R}$ be differentiable such that, for $q_{1}>1$, $\psi\left(t^{1 / q_{1}}\right)$ is a convex function and $\psi(0)=0$. Also, let $0<\alpha<1, g \in H^{1}\left(a_{1}, b_{1}\right)$, and let ${ }^{C F} I_{b_{1}}^{\alpha}$ be defined by (2.9). If $\frac{1}{p_{1}}+\frac{1}{q_{1}}=1$, then the following inequalities hold:

$$
\begin{aligned}
& \int_{a_{1}}^{b_{1}}\left|\left({ }^{C F} I_{b_{1}}^{\alpha} g\right)(t)-\frac{1-\alpha}{B(\alpha)} g(t)\right|^{1-q_{1}} \psi^{\prime}\left(\left|\left({ }^{C F} I_{b_{1}}^{\alpha} g\right)(t)-\frac{1-\alpha}{B(\alpha)} g(t)\right|\right)|g(t)|^{q_{1}} d t \\
& \quad \leq \frac{q_{1}}{C_{1}^{q_{1}}} \psi\left(C_{1}\left(\int_{a_{1}}^{b_{1}}|g(t)|^{q_{1}} d t\right)^{1 / q_{1}}\right) \\
& \quad \leq \frac{q_{1}}{C_{1}^{q_{1}}\left(b_{1}-a_{1}\right)} \int_{a_{1}}^{b_{1}} \psi\left(\left(b_{1}-a_{1}\right)^{1 / q_{1}} C_{1}|g(t)|\right) d t,
\end{aligned}
$$

where $C_{1}$ is defined as in (3.8). If $\psi\left(t^{1 / q_{1}}\right)$ is a concave function, then reverse inequalities hold.

Proof Using the same method as the proof of Theorem 3.1, inequalities follow from Theorem 2.2.

When $\psi(t)=t^{p_{1}+q_{1}}$ in Theorem 3.4, we obtain the following corollary.

Corollary 3.4 Let $0<\alpha<1, g \in H^{1}\left(a_{1}, b_{1}\right)$, and let ${ }^{C F} I_{b_{1}}^{\alpha}$ be defined by (2.9). Also let $\frac{1}{p_{1}}+$ $\frac{1}{q_{1}}=1$. Then the following inequalities hold:

$$
\begin{aligned}
& \int_{a_{1}}^{b_{1}}\left|\left({ }^{C F} I_{b_{1}}^{\alpha} g\right)(t)-\frac{1-\alpha}{B(\alpha)} g(t)\right|^{p_{1}}|g(t)|^{q_{1}} d t \\
& \quad \leq \frac{q_{1} C_{1}^{p_{1}}}{p_{1}+q_{1}}\left(\int_{a_{1}}^{b_{1}}|g(t)|^{q_{1}} d t\right)^{\left(p_{1}+q_{1}\right) / q_{1}} \\
& \quad \leq \frac{q_{1} C_{1}^{p_{1}}\left(b_{1}-a_{1}\right)^{p_{1} / q_{1}}}{p_{1}+q_{1}} \int_{a_{1}}^{b_{1}}|g(t)|^{p_{1}+q_{1}} d t,
\end{aligned}
$$

where $C_{1}$ is defined as in (3.8).

\section{Examples}

Below, we will show the application of our main results with two examples.

Example 4.1 In Corollary 3.1, let $g(t)=e^{t}, \alpha=\frac{1}{2}, p_{1}=q_{1}=2, M(\alpha)=\alpha$, and $t \in\left[a_{1}, b_{1}\right]=$ $[1,3]$. Then $\lambda=-1, M\left(\frac{1}{2}\right)=\frac{1}{2}$, and $C=\sqrt{\frac{1-e^{-4}}{2}}$. So, we obtain

$$
\begin{aligned}
\left({ }_{1}^{C F R} D^{\frac{1}{2}} g\right)(t) & =\left({ }_{1}^{C F R} D^{\frac{1}{2}} g\right)(t)=\frac{d}{d t} \int_{1}^{t} e^{s} e^{-(t-s)} d s=\int_{1}^{t} \frac{\partial}{\partial t}\left(e^{-t+2 s}\right) d s+e^{t} \\
& =-\int_{1}^{t} e^{-t+2 s} d s+e^{t}=\frac{e^{t}+e^{-t+2}}{2} .
\end{aligned}
$$


Then we apply Corollary 3.1 to obtain the following inequalities:

$$
\begin{aligned}
\int_{1}^{3}\left|\left({ }_{1}^{C F R} D^{\frac{1}{2}} g\right)(t)\right|^{2}\left|g^{\prime}(t)\right|^{2} d t & =\int_{1}^{3}\left|\frac{e^{t}+e^{-t+2}}{2}\right|^{2} e^{2 t} d t \\
& \leq \frac{1-e^{-4}}{4}\left(\int_{1}^{3} e^{2 t} d t\right)^{2} \leq \frac{1-e^{-4}}{2} \int_{1}^{3} e^{4 t} d t .
\end{aligned}
$$

Example 4.2 In Corollary 3.3, let $g(t)=\sin t, \alpha=\frac{1}{2}, p_{1}=q_{1}=2, B(\alpha)=1-\alpha$, and $t \in$ $\left[a_{1}, b_{1}\right]=\left[\frac{\pi}{2}, \pi\right]$. Then $\lambda=-1, B\left(\frac{1}{2}\right)=\frac{1}{2}$, and $C_{1}=\sqrt{\pi-\frac{\pi}{2}}$. So, we obtain

$$
\left({ }_{\frac{\pi}{2}}^{C F} I^{\frac{1}{2}} g\right)(t)=\left({ }_{\frac{\pi}{2}}^{C F} I^{\frac{1}{2}} \sin \right)(t)=\sin t+\int_{\frac{\pi}{2}}^{t} \sin (s) d s=\sin t-\cos t
$$

Then we apply Corollary 3.3 to obtain the following inequalities:

$$
\begin{aligned}
& \int_{\frac{\pi}{2}}^{\pi}\left|\left({ }_{\frac{\pi}{2}}^{C F} I^{\frac{1}{2}} g\right)(t)-\frac{1-\alpha}{B(\alpha)} g(t)\right|^{2}|g(t)|^{2} d t \\
& \quad=\int_{\frac{\pi}{2}}^{\pi}|\sin t-\cos t-\sin t|^{2}|\sin t|^{2} d t \\
& \quad=\int_{\frac{\pi}{2}}^{\pi} \cos ^{2} t \sin ^{2} t d t \leq \frac{\pi-\frac{\pi}{2}}{2}\left(\int_{\frac{\pi}{2}}^{\pi} \sin ^{2} t d t\right)^{2} \\
& \quad \leq \frac{\pi}{4}\left(\pi-\frac{\pi}{2}\right) \int_{\frac{\pi}{2}}^{\pi} \sin ^{4} t d t .
\end{aligned}
$$

\section{Conclusion}

Caputo-Fabrizio operator has recently started to play an important role in modeling of a class of real world dissipative phenomena [35]. In fact some real data have confirmed that this operator is important for describing the dynamics of specific classes of real world problems. At the same time new mathematical generalizations of this operator were developed. In our manuscript, with the help of inequalities obtained by Andrić et al. [15], we proposed, within four theorems and their related corollaries, several Opial-type integral inequalities for Caputo-Fabrizio operators. Finally, we analyzed two illustrative examples carefully. The results reported in this manuscript can find applications within the evaluation of the existence and uniqueness of initial and boundary value problems related to diffusion process within the Caputo-Fabrizio operators.

\section{Acknowledgements}

The authors would like to thank the referees for their useful comments and remarks

Funding

No funding.

Competing interests

The authors declare that they have no competing interests.

Authors' contributions

All authors contributed to each part of this work equally, and they all read and approved the final manuscript.

\section{Author details}

'Department of Mathematics, Faculty of Arts and Sciences, Bolu Abant Izzet Baysal University, Bolu, Turkey. ${ }^{2}$ Department of Mathematics, Faculty of Arts and Sciences, Çankaya University, Ankara, Turkey. ${ }^{3}$ Institutes of Space Sciences, Magurele-Bucharest, Romania. 


\section{Publisher's Note}

Springer Nature remains neutral with regard to jurisdictional claims in published maps and institutional affiliations.

\section{Received: 9 August 2018 Accepted: 2 December 2018 Published online: 06 December 2018}

\section{References}

1. Abdeljawad, T., Baleanu, D.: On fractional derivatives with exponential kernel and their discrete versions. Rep. Math. Phys. 80, 1-27 (2017)

2. Agarwal, R.P.: Sharp Opial-type inequalities involving $r$-derivatives and their applications. Tohoku Math. J. 47, 567-593 (1995)

3. Agarwal, R.P., Lakshmikantham, V.: Uniqueness and Nonuniqueness Criteria for Ordinary Differential Equations. World Scientific, Singapore (1993)

4. Agarwal, R.P., Pang, P.Y.H.: Opial Inequalities with Applications in Differential and Difference Equations. Kluwer Academic, Dordrecht (1995)

5. Agarwal, R.P., Pang, P.Y.H.: Opial-type inequalities involving higher order derivatives. J. Math. Anal. Appl. 189, 85-103 (1995)

6. Agarwal, R.P., Pang, P.Y.H.: Remarks on the generalizations of Opial's inequality. J. Math. Anal. Appl. 190, 559-577 (1995)

7. Anastassiou, G.A.: Opial type inequalities involving functions and their ordinary and fractional derivatives. Commun. Appl. Anal. 4(4), 547-560 (2000)

8. Anastassiou, G.A.: Opial-type inequalities involving fractional derivatives of two functions and applications. Comput. Math. Appl. 48, 1701-1731 (2004)

9. Anastassiou, G.A.: Opial type inequalities involving Riemann-Liouville fractional derivatives of two functions with applications. Math. Comput. Model. 48, 344-374 (2008)

10. Anastassiou, G.A.: Balanced fractional Opial inequalities. Chaos Solitons Fractals 42, 1523-1528 (2009)

11. Anastassiou, G.A.: Opial-type inequalities for functions and their ordinary and balanced fractional derivatives. J. Comput. Anal. Appl. 14(5), 862-879 (2012)

12. Anastassiou, G.A., Goldstein, J.A.: Fractional Opial-type inequalities and fractional differential equations. Results Math. $41,197-212(2002)$

13. Anastassiou, G.A., Koliha, J.J., Pečarić, J.: Opial type $L_{p}$-inequalities for fractional derivatives. Int. J. Math. Math. Sci. 31(2), 85-95 (2002)

14. Andrić, M., Barbir, A., Farid, G., Pečarić, J: More on certain Opial-type inequality for fractional derivatives. Nonlinear Funct. Anal. Appl. 19(4), 563-583 (2014)

15. Andrić, M., Barbir, A., Farid, G., Pečarić, J.: Opial-type inequality due to Agarwal-Pang and fractional differential inequalities. Integral Transforms Spec. Funct. 25(4), 324-335 (2014)

16. Andrić, M., Pečarić, J., Perić, l.: Improvements of composition rule for the Canavati fractional derivatives and applications to Opial-type inequalities. Dyn. Syst. Appl. 20, 383-394 (2011)

17. Andrić, M., Pečarić, J., Perić, l.: An Opial-type inequality for fractional derivatives of two functions. Fract. Differ. Calc. 3(1), 55-68 (2013)

18. Andrić, M., Pečarić, J., Perić, I: Composition identities for the Caputo fractional derivatives and applications to Opial-type inequalities. Math. Inequal. Appl. 16(3), 657-670 (2013)

19. Andrić, M., Pečarić, J., Perić, l.: A multiple Opial type inequality for the Riemann-Liouville fractional derivatives. J. Math. Inequal. 7(1), 139-150 (2013)

20. Atanacković, T.M., Pilipović, S., Zorica, D.: Survey paper properties of the Caputo-Fabrizio fractional derivative and its distributional settings. Fract. Calc. Appl. Anal. 21(1), 29-44 (2018)

21. Bainov, D., Simeonov, P.: Integral Inequalities and Applications. Kluwer Academic, Dordrecht (1992)

22. Boyd, D.W.: Best constants in inequalities related to Opial's inequality. J. Math. Anal. Appl. 25, 378-387 (1969)

23. Caputo, M., Fabrizio, M.: A new definition of fractional derivative without singular kernel. Prog. Fract. Differ. Appl. $1(2)$, 73-85 (2015)

24. Cheung, W.S.: On Opial-type inequalities in two variables. Aequ. Math. 38, 236-244 (1989)

25. Cheung, W.S.: Some new Opial-type inequalities. Mathematika 37, 136-142 (1990)

26. Cheung, W.S.: Generalizations of Opial-type inequalities in two variables. Tamkang J. Math. 22(1), 43-50 (1991)

27. Cheung, W.S.: Some generalized Opial-type inequalities. J. Math. Anal. Appl. 162(2), 317-321 (1991)

28. Cheung, W.S.: Opial-type inequalities with $m$ functions in $n$ variables. Mathematika 39, 319-326 (1992)

29. Farid, G., Pečarić, J.: Opial-type integral inequalities for fractional derivatives. Fract. Differ. Calc. 2(1), 31-54 (2012)

30. Farid, G., Pečarić, J.: Opial-type integral inequalities for fractional derivatives II. Fract. Differ. Calc. 2(2), 139-155 (2012)

31. Farid, G., Pečarić, J.: Opial-type integral inequalities for Widder derivatives and linear differential operators. Int. J. Anal. Appl. 7(1), 38-49 (2015)

32. Farid, G., Pečarić, J., Tomovski, Z:: Opial-type integral inequalities for fractional integral operator involving Mittag-Leffler function. Fract. Differ. Calc. 5(1), 93-106 (2015)

33. Farid, G., Pečarić, J., Tomovski, Z:: Generalized Opial-type inequalities for differential and integral operators with special kernels in fractional calculus. J. Math. Inequal. 10(4), 1019-1040 (2016)

34. Fink, A.M.: On Opial's inequality for $f^{(n)}$. Proc. Am. Math. Soc. 115, 177-181 (1992)

35. Hristov, J.: Transient heat diffusion with a non-singular fading memory: from the Cattaneo constitutive equation with Jeffrey's kernel to the Caputo-Fabrizio time-fractional derivative. Therm. Sci. 20, 757-762 (2016)

36. Hristov, J.: Derivation of fractional Dodson equation and beyond: transient mass diffusion with a non-singular memory and exponentially fading-out diffusivity. Prog. Fract. Differ. Appl. 3(4), 255-270 (2017)

37. Hristov, J.: Derivatives with non-singular kernels from the Caputo-Fabrizio definition and beyond: appraising analysis with emphasis on diffusion models. Front. Fract. Calc. 1, 270-342 (2017)

38. Koliha, J.J., Pečarić, J.: Weighted Opial inequalities. Tamkang J. Math. 33(1), 83-92 (2002)

39. Li, J.-D.: Opial-type inequalities involving several higher order derivatives. J. Math. Anal. Appl. 167, 98-110 (1992)

40. Lin, C.T.: Some generalizations of Opial's inequality. Tamkang J. Math. 16, 123-129 (1985) 
41. Losada, J., Nieto, J.: Properties of a new fractional derivative without singular kernel. Prog. Fract. Differ. Appl. 1(2), 87-92 (2015)

42. Mitrinovič, D.S., Pečarić, J., Fink, A.M.: Inequalities Involving Functions and Their Integrals and Derivatives. Kluwer Academic, Dordrecht (1991)

43. Opial, Z:: Sur une inégalité. Ann. Pol. Math. 8, 29-32 (1960)

44. Pachpatte, B.G.: On Opial-type integral inequalities. J. Math. Anal. Appl. 120, 547-556 (1986)

45. Pachpatte, B.G.: On some new generalizations of Opial inequality. Demonstr. Math. 19, $281-291$ (1986)

46. Pachpatte, B.G.: On certain integral inequalities related to Opial's inequality. Period. Math. Hung. 17, 119-125 (1986)

47. Pachpatte, B.G.: On inequalities of Opial type. Demonstr. Math. 25, 35-45 (1992)

48. Pang, P.Y.H., Agarwal, R.P.: On an Opial type inequality due to Fink. J. Math. Anal. Appl. 196(2), 748-753 (1995)

49. Ross, S.L.: Differential Equations. Wiley, New York (1984)

50. Sarıkaya, M.Z., Budak, H.: New inequalities of Opial-type for conformable fractional integrals. Turk. J. Math. 41, 1164-1173 (2017)

51. Schwartz, L.: Mathematics for the Physical Sciences. Addison-Wesley, Paris (1966)

52. Tateishi, A.A., Ribeiro, H.V., Lenzi, E.K.: The role of fractional time-derivative operators on anomalous diffusion. Front. Phys. (2017). https://doi.org/10.3389/fphy.2017.00052

53. Tomovski, Z., Pecarić, J., Farid, G.: Weighted Opial-type inequalities for fractional integral and differential operators involving generalized Mittag-Leffler function. Eur. J. Pure Appl. Math. 10(3), 419-439 (2017)

54. Yang, G.S.: A note on an inequality similar to Opial inequality. Tamkang J. Math. 18, 101-104 (1987)

\section{Submit your manuscript to a SpringerOpen ${ }^{\circ}$ journal and benefit from:}

- Convenient online submission

- Rigorous peer review

Open access: articles freely available online

- High visibility within the field

Retaining the copyright to your article

Submit your next manuscript at $\gg$ springeropen.com 